\title{
A New Lowpass Filter Unit Cell with Sharp Roll-off and Improved Stopband Performance in Coplanar Waveguide Technology
}

\author{
Abolfazl Bijari' ${ }^{1}$, Mahdi Mohebrad ${ }^{1}$, \\ ${ }^{1}$ Faculty of Electronics, Department of Electrical and Computer Engineering, University of Birjand, Birjand, Iran \\ *corresponding author, E-mail: a.bijari@birjand.ac.ir
}

\begin{abstract}
In this paper, a new compact unit cell for a coplanar waveguide (CPW) lowpass filter (LPF) is proposed. By combining a pair of coupled parallel stepped impedance resonators (SIRs) and high impedance short stubs in the CPW line, a fifth-order elliptic lowpass filter unit cell (LUC) is designed. The extra transmission zero introduced by parallel coupled SIRs is used to extend the stopband and increase the roll-off rate. The characteristics of the proposed LUC is investigated to achieve a sharp roll-off and a wide stopband. The measured results are in accordance with the simulated results. It has an insertion loss less than $0.9 \mathrm{~dB}$ from dc to 6 $\mathrm{GHz}$, and a wide $-15 \mathrm{~dB}$ stopband from 7.5 to $18 \mathrm{GHz}$. In addition, the filter dimensions are as small as $4.9 \mathrm{~mm} \times 8.7$ $\mathrm{mm}$, that is, $0.046 \lambda_{\mathrm{g}}{ }^{2}$, where $\lambda_{\mathrm{g}}$ is the guided wavelength at the cut-off frequency. The filter structure is simple and easy to fabricate as well.
\end{abstract}

\section{Introduction}

Compact size and high performance lowpass filters (LPFs) are widely used in radio frequency (RF) and microwave front-end systems to suppress undesired harmonics and spurious frequency bands. The most conventional LPFs use a cascade of multiple unit cells to achieve a sharp roll-off and wide stopband response [1-3]. However, increasing the number of unit cells will also increase the size and insertion loss of the filter. Hence, the design of an elliptic-function LPF unit cell (LUC) with sharp roll-off and wide stopband is the most effective method of obtaining a compact LPF with high performance. Compared to microstrip technology, the coplanar waveguide (CPW) technology is more attractive as a result of its uniplanar structure, low dispersion effect, wide impedance range and substrate thickness insensitivity [4].

Resonators are the key components of LUCs and several resonators have been studied over the years. The seriesconnected parallel resonators in CPW technology can be implemented by open complementary split ring resonators (OCSRRs) [2,5], defected ground structure (DGS) [6,7] and by etching interdigital capacitances in the signal strip of the CPW with an electrical short in one of the fingers $[1,8,9]$. The shunt-connected series resonators can be implemented by stepped impedance resonators (SIRs) $[1,10]$ and electromagnetic bandgap (EBG) structures [11,12].

However, conventional resonators do not only have large sizes, but also have a gradual transition band. Hettak et al. [9] and Sor et al. [13] proposed several series and shunt stubs on the signal strip and ground planes of the CPW to facilitate the design of parallel resonators and reduce the LUC size. No and Hwang [1] proposed two different CPW LUCs and demonstrated a LPF by cascading two unit cells and a DGS. The slots on the signal strip and ground planes of the CPW were used to realize the third-order elliptic LUCs. The LUCs with different structures present the same cut-off frequency, but their performance suffers from narrow stopband and gradual roll-off. The stopband performance of the LPF is improved by cascading two unit cells and a DGS, but the size is increased and return loss is slightly improved. It has been proposed that the EBG structures should be used in extending the stopband [12]. Zuo et al. [11], demonstrated an EBG unit cell based on CPW which has been symmetrically etched on both the signal strip and the ground planes for producing the desired inductance and capacitance. The EBG unit cell has the characteristics of an elliptic-function and the two transmission zeros in the stopband are used to enhance the rejection level of the stopband. However, it presents relatively high radiation loss at high frequencies and gradual roll-off. An elliptic-function CPW LUC was implemented using the meandering strip and backside metallic patterns with a compact size [3]. However, the LUC shows some disadvantages such as gradual roll-off and its first spurious band is relatively close to the cut-off frequency.

In this paper, an elliptic-function CPW LUC based on coupled parallel SIRs is proposed to obtain a compact size, sharp roll-off and wide stopband performance. The equivalent circuit of the proposed LUC is extracted to analyze its performance. The electromagnetic fields were simulated to prove its property as well. The equivalent LC circuit and full-wave simulation is performed with Advanced Design System (ADS) and Ansoft HFSS, respectively. The proposed LUC is then fabricated on a low-cost FR4 substrate and experimentally verified with the measured results.

\section{Proposed LUC design}

Fig. 1 presents the proposed CPW LUC and its corresponding lossless transmission line circuit. The LUC 
consists of three high impedance short stubs and a symmetric pair of parallel coupled SIRs with folded open stubs.

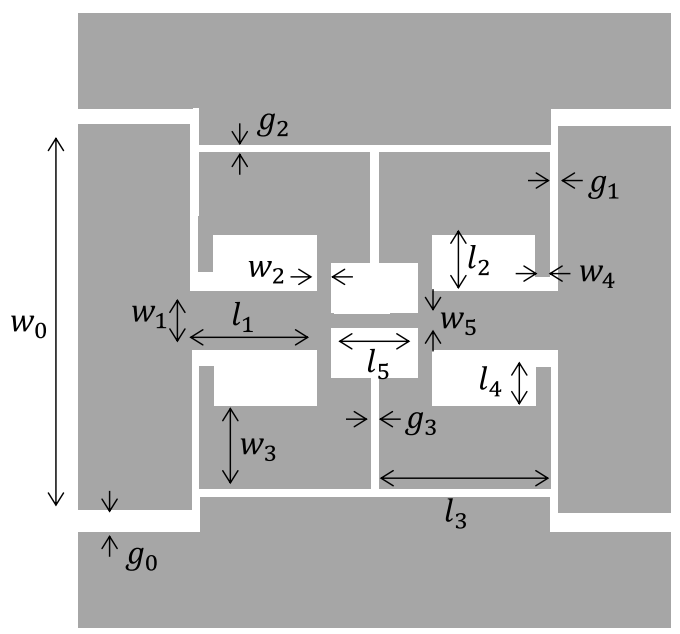

(a)

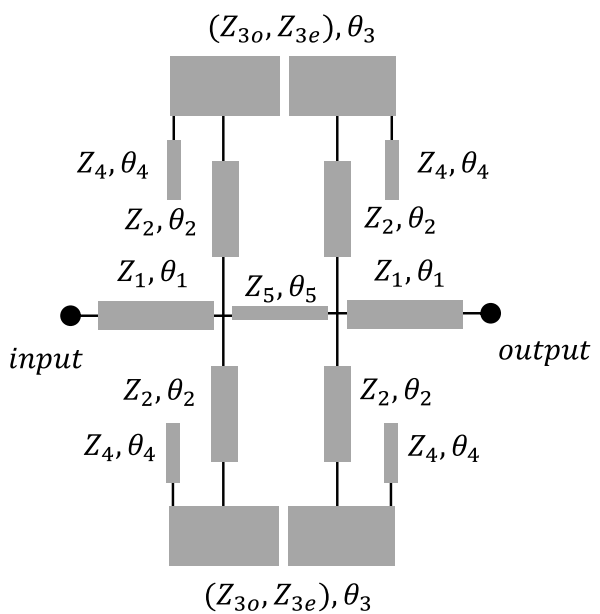

(b)

Figure 1: (a) Layout of the proposed LUC $\left(w_{0}=7.5 \mathrm{~mm}\right.$, $g_{0}=0.6 \mathrm{~mm}, w_{1}=1.4 \mathrm{~mm}, l_{1}=1.5 \mathrm{~mm}, g_{1}=0.1 \mathrm{~mm}, w_{2}=0.3$ $\mathrm{mm}, l_{2}=1 \mathrm{~mm}, g_{2}=0.1 \mathrm{~mm}, w_{3}=1.5 \mathrm{~mm}, l_{3}=2.2 \mathrm{~mm}$, $g_{3}=0.1 \mathrm{~mm}, w_{4}=0.2 \mathrm{~mm}, l_{4}=0.9 \mathrm{~mm}, w_{5}=0.15 \mathrm{~mm}$ and $l_{5}=1.1 \mathrm{~mm}$ ) and (b) Its corresponding transmission line circuit.

As shown, the structure is symmetrical and the input/output sections $\left(Z_{1}\right)$ of the proposed LUC are the series short stubs connected with the $50 \Omega$ input/output ports. The parallel coupled SIRs $\left(Z_{2}, Z_{3}\right)$ are connected on the symmetrical plane of the input/output sections and used to obtain sharp roll-off, and wide stopband with multiple transmission zeros. The folded stubs $\left(Z_{4}\right)$ at the end of the SIRs are also utilized to increase the loading capacitance of the input/output ports.

\subsection{Lumped element model of the proposed LUC}

The equivalent LC circuit of the proposed LUC is shown in Fig. 2, in which the parasitic capacitances are ignored. As shown, $L_{1}$ models the inductances of series short stubs between input/output ports and SIRs. The shunt narrow strip and the open stubs in the SIRs are represented by $L_{2}$ and $C_{2}$, respectively. The loading capacitance to the input/output ports due to the folded stubs at the end of the SIRs can be modeled by $C_{1} . C_{3}$ denotes the coupling capacitance between SIRs and $L_{3}$ represents the inductance of the high impedance section between the centers of the two SIRs.

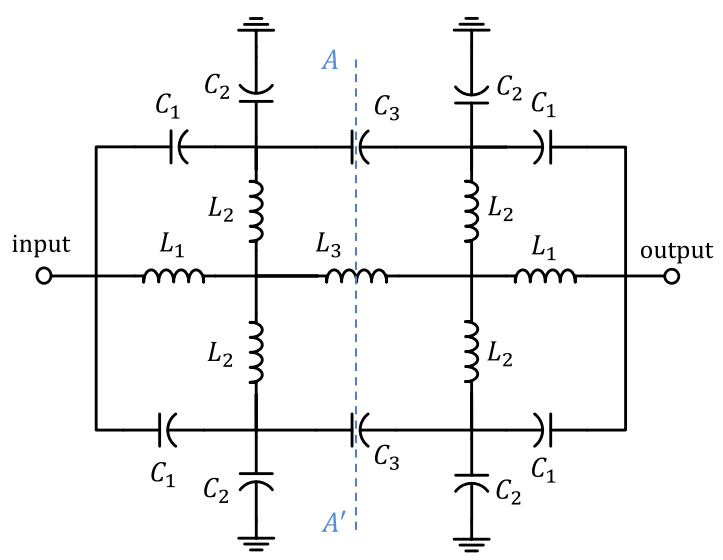

Figure 2: Equivalent LC circuit of the proposed LUC.

Since the structure of the proposed LUC is symmetrical, the scattering parameters $\left(S_{21}\right.$ and $\left.S_{11}\right)$ can be derived using even-odd mode analysis, and are given by [14]:

$$
\begin{aligned}
S_{21} & =\frac{Y_{0}\left(Y_{\text {ino }}-Y_{\text {ine }}\right)}{\left(Y_{0}+Y_{\text {ine }}\right)\left(Y_{0}+Y_{\text {ino }}\right)} \\
S_{11} & =\frac{Y_{0}^{2}-Y_{\text {ino }} Y_{\text {ine }}}{\left(Y_{0}+Y_{\text {ine }}\right)\left(Y_{0}+Y_{\text {ino }}\right)}
\end{aligned}
$$

where, $Y_{0}$ is the characteristic admittance. $Y_{\text {ine }}$ and $Y_{\text {ino }}$ are even and odd mode input admittances, respectively. As shown in Fig. 3, the equivalent LC circuit shown in Fig. 2 can be divided into two sections along the symmetric line of $\mathrm{A}-\mathrm{A}^{\prime}$, an open circuit for even mode and a short circuit for odd mode.

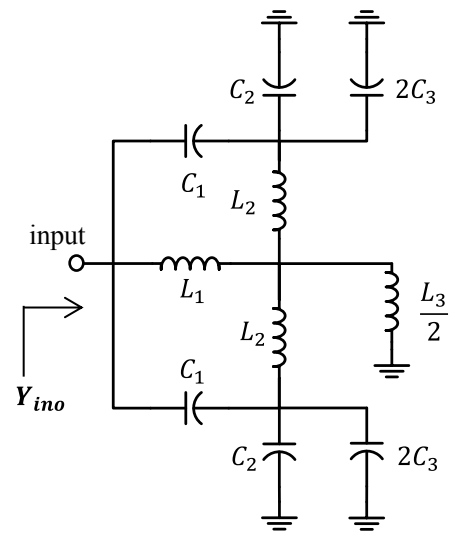

(a)

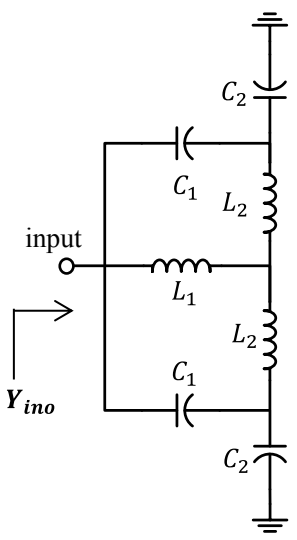

(b)
Figure 3: Equivalent LC circuit of (a) even mode and (b) odd mode of the proposed LUC. 
The even and odd mode input admittances can be expressed as:

$$
Y_{\text {ine }}=2 j \omega C_{2} \frac{1-C_{1}\left(2 L_{1}+L_{2}\right) \omega^{2}}{1-\left(C_{1}+C_{2}\right)\left(2 L_{1}+L_{2}\right) \omega^{2}}
$$

$$
\begin{aligned}
& Y_{\text {ino }}= \\
& -2 j \frac{C_{x} C_{1}\left(L_{2}\left(2 L_{1}+L_{3}\right)+2 L_{1} L_{3}\right) \omega^{4}-\left(C_{x} L_{3}+C_{y} L_{2}+2 C_{1} L_{1}\right) \omega^{2}+1}{\omega\left(-C_{y}\left(\left(2 L_{1}+L_{3}\right) L_{2}+2 L_{1} L_{3}\right) \omega^{2}+2 L_{1}+L_{3}\right)}
\end{aligned}
$$

where,

$$
\begin{aligned}
& C_{x}=2 C_{3}+C_{2} \\
& C_{y}=2 C_{3}+C_{2}+C_{1}
\end{aligned}
$$

Transmission zeros occur when $\mathrm{S}_{21}=0$. Consequently, transmission zeros can be obtained when $Y_{\text {ino }}=Y_{\text {ine. }}$. According to (3), $Y_{\text {ine }}$ does not depend on $C_{3}$ and $L_{3}$. Fig. 4 shows the relations between the even and odd mode input admittances ( $Y_{\text {ine }}$ and $Y_{\text {ino}}$ ) and the first and second transmission zeros $\left(f_{\mathrm{tz} 1}\right.$ and $\left.f_{\mathrm{tz} 2}\right)$ under different values of $C_{3}$ and $L_{3}$.

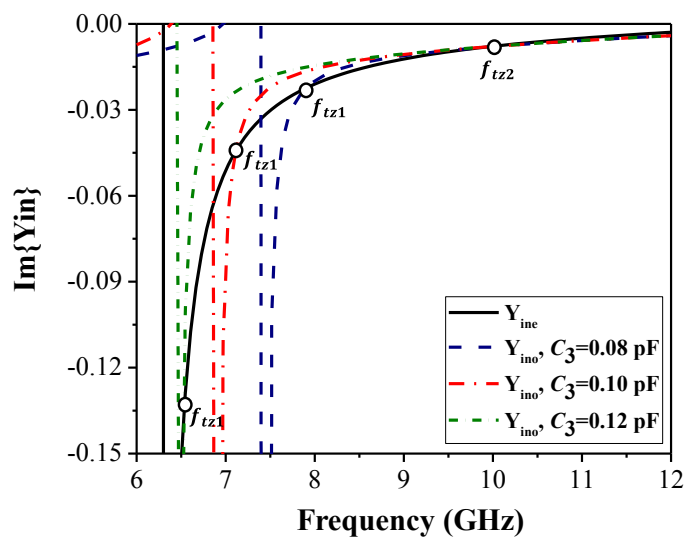

(a)

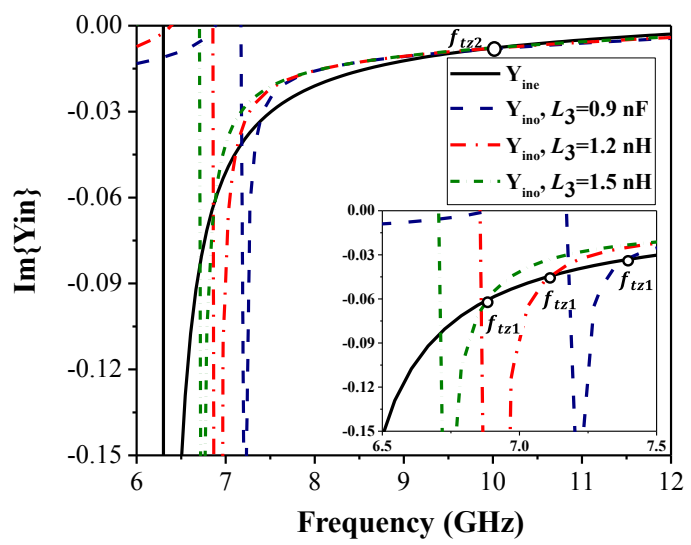

(b)

Figure 4: Relations between the even and odd mode input admittances and transmission zeros for the proposed LUC ( $L_{1}=0.9 \mathrm{nH}, C_{1}=0.1 \mathrm{pF}, L_{2}=0.4 \mathrm{nH}$ and $C_{2}=0.4 \mathrm{pF}$ are fixed) under different values of (a) $C_{3}$ (with $L_{3}=1.2$ $\mathrm{nH}$ ) and (b) $L_{3}$ (with $C_{3}=0.1 \mathrm{pF}$ ).
As shown in Fig. 4, the first transmission zero $\left(f_{\mathrm{tzl}}\right)$ shifts to lower frequency as $C_{3}$ or $L_{3}$ increased while the second transmission zero $\left(f_{\mathrm{tz} 2}\right)$ remains almost unmoved. Moreover, the transmission poles in the passband can be obtained when $\mathrm{S}_{11}=0$, which gives $Y_{0}^{2}=Y_{\text {ine }} \times Y_{\text {ino. Fig. } 5 \text { shows the relations }}$ between the $N(f)=Y_{0}^{2}-Y_{\text {ine }} \times Y_{\text {ino }}$ and the first and second transmission poles $\left(f_{\mathrm{tp} 1}\right.$ and $\left.f_{\mathrm{tp} 2}\right)$ under different values of $C_{3}$ and $L_{3}$.

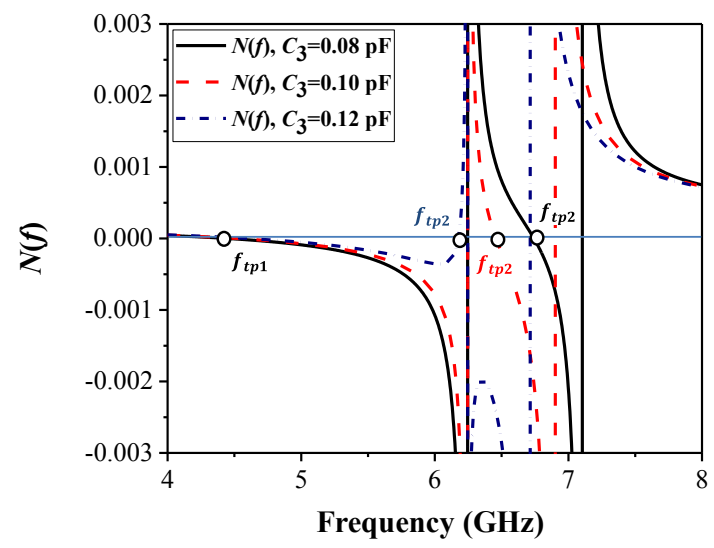

(a)

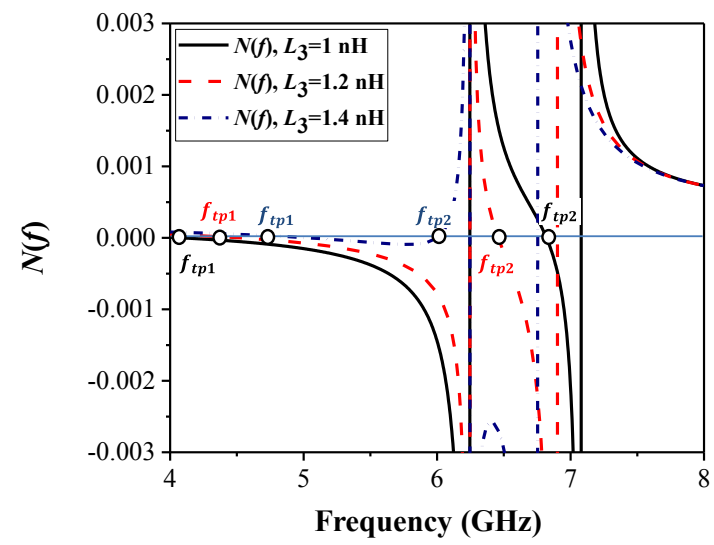

(b)

Figure 5: Relations between the $N(f)$ and transmission poles for the proposed LUC $\left(L_{1}=0.9 \mathrm{nH}, C_{1}=0.1 \mathrm{pF}\right.$, $L_{2}=0.4 \mathrm{nH}$ and $C_{2}=0.4 \mathrm{pF}$ are fixed) under different values of (a) $C_{3}$ (with $L_{3}=1.2 \mathrm{nH}$ ) and (b) $L_{3}$ (with $C_{3}=0.1$ $\mathrm{pF})$.

As shown in Fig. 5, when the $C_{3}$ and $L_{3}$ increase, the second transmission pole further shifts to lower frequency. Consequently, it is impossible to simultaneously achieve a sharp roll-off and high passband return loss by only changing $C_{3}$ and $L_{3}$. Fig. 6 shows the relations between the even and odd mode input admittances ( $Y_{\text {ine }}$ and $Y_{\text {ino }}$ ) and the first and second transmission zeros $\left(f_{\mathrm{tz} 1}\right.$ and $\left.f_{\mathrm{tz} 2}\right)$ under different values of $C_{1}$. The frequency location of the transmission zeros can be controlled by suitably adjusting $C_{1}$. As shown in Fig. 6, the transmission zeros shift toward the passband edge as $C_{1}$ increased while the transmission poles remain unmoved. Therefore, the first transmission zero can be produced close to the passband to improve the roll-off rate of the proposed LUC. 


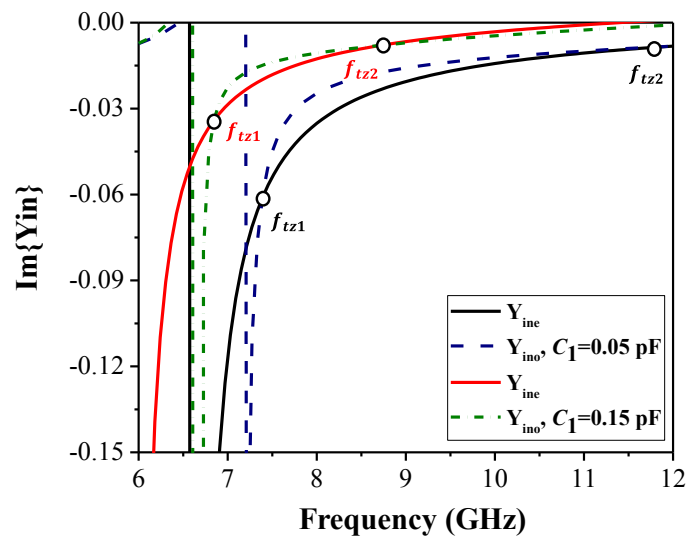

(a)

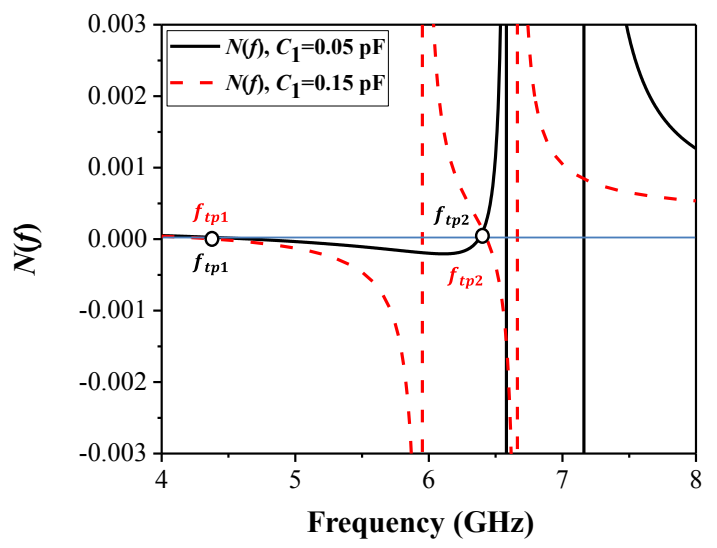

(b)

Figure 6: Frequency location of the (a) transmission zeros and (b) transmission poles under different values of $C_{1}$ $\left(L_{1}=0.9 \mathrm{nH}, L_{2}=0.4 \mathrm{nH}, C_{2}=0.4 \mathrm{pF}, C_{3}=0.1 \mathrm{pF}\right.$ and $L_{3}=1.2 \mathrm{nH}$ are fixed).

By properly locating the transmission zeros and poles produced by the coupled SIRs and series short stubs, not only sharp roll-off and wide stopband, but also size reduction and high passband return loss can be addressed simultaneously. The equivalent LC circuit values of inductance and capacitance can be extracted approximately as $[4,15]$ :

$$
\begin{aligned}
& L_{1} \approx \frac{Z_{1} \sqrt{\varepsilon_{e f f}}}{c} l_{1} \\
& C_{1} \approx 2 \varepsilon_{e f f} \varepsilon_{0} \frac{K\left(k^{\prime}\right)}{K(k)} \\
& L_{2} \approx \frac{Z_{2} \sqrt{\varepsilon_{e f f}}}{2 c} l_{2} \\
& C_{2} \approx \frac{2 \sqrt{\varepsilon_{e f f}}}{Z_{3 e} c} l_{3} \\
& L_{3} \approx \frac{Z_{5} \sqrt{\varepsilon_{e f f}}}{c} l_{4} \\
& C_{3} \approx \frac{\left(Z_{3 e}-Z_{3 o}\right) \sqrt{\varepsilon_{e f f}}}{Z_{3 e} Z_{3 o} c} l_{3}
\end{aligned}
$$

where, $\varepsilon_{\text {eff }}$ is the CPW effective dielectric constant and $c$ denotes the velocity of light in free space. $Z_{\mathrm{i}}$ represents the characteristic impedance of the $\mathrm{CPW}$ line and $K$ is the complete elliptical integral of the first kind. The arguments $k$ and $k^{\prime}$ are dependent on the geometry of the CPW line. $Z_{3 \mathrm{e}}$ and $Z_{30}$ are the even and odd mode impedances of the coupled lines associated with SIRs.

The fifth-order elliptic-function LUC is designed for the cut-off frequency of $f_{\mathrm{c}}=7 \mathrm{GHz}$, with pass-band ripple of $L_{\mathrm{Ar}}=0.2 \mathrm{~dB}$, stopband attenuation of $L_{\mathrm{As}}=15 \mathrm{~dB}$ and equalripple stopband starting frequency of $f_{\mathrm{s}}=7.25 \mathrm{GHz}$. The element values of the proposed LUC in the equivalent LC circuit can be obtained and modified by Advanced Design System (ADS) to yield the desired frequency response as follows: $L_{1}=0.85 \mathrm{nH}, C_{1}=0.025 \mathrm{pF}, L_{2}=0.3 \mathrm{nH}, C_{2}=0.4 \mathrm{pF}$, $L_{3}=1.55 \mathrm{nH}$ and $C_{3}=0.12 \mathrm{pF}$. By assuming high impedances of $Z_{1}=115 \Omega, Z_{2}=140 \Omega$ and $Z_{5}=190 \Omega$ and low impedance of $Z_{3}=30 \Omega$, the initial dimensions of the LUC can be calculated by equations (7)-(12).

\subsection{Simulation results and discussion}

The final dimension is obtained by curve fitting the electromagnetic (EM) response (using Ansoft HFSS) to that of the circuit model as follows: $w_{0}=7.5 \mathrm{~mm}, g_{0}=0.6 \mathrm{~mm}$, $w_{1}=1.4 \mathrm{~mm}, l_{1}=1.5 \mathrm{~mm}, g_{1}=0.1 \mathrm{~mm}, w_{2}=0.3 \mathrm{~mm}, l_{2}=1 \mathrm{~mm}$, $g_{2}=0.1 \mathrm{~mm}, w_{3}=1.5 \mathrm{~mm}, l_{3}=2.2 \mathrm{~mm}, g_{3}=0.1 \mathrm{~mm}, w_{4}=0.2 \mathrm{~mm}$, $l_{4}=0.9 \mathrm{~mm}, w_{5}=0.15 \mathrm{~mm}$ and $l_{5}=1.1 \mathrm{~mm}$. The comparison between the EM and circuit simulations is shown in Fig. 7.

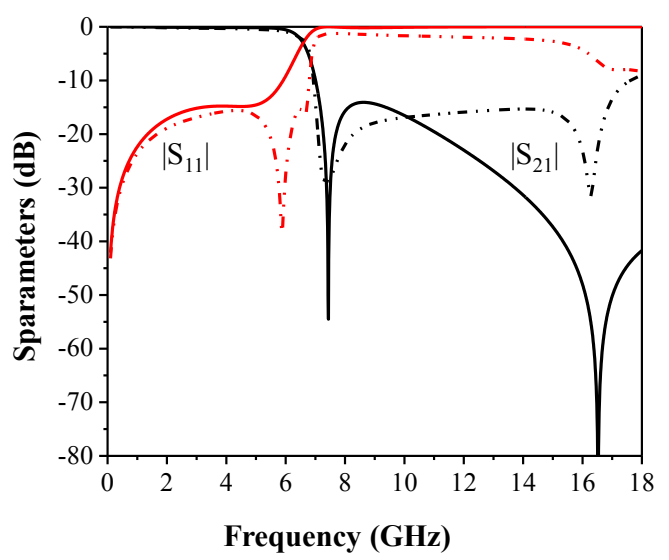

Figure 7: EM (solid line) and equivalent LC circuit (dash line) simulations of the proposed LUC.

The EM field distributions of the proposed LUC at the frequency in the passband ( $4 \mathrm{GHz}$ ) are shown in Fig. 8. As it can be seen, the electric field is concentrated around the capacitance-load parallel coupled lines and the folded stubs of the SIRs which represent the capacitance. Moreover, the high magnetic field distribution is mainly located around the series short stubs. It is clear from the field distributions that there is a strong coupling between input and output ports at the passband frequency of $4 \mathrm{GHz}$. 

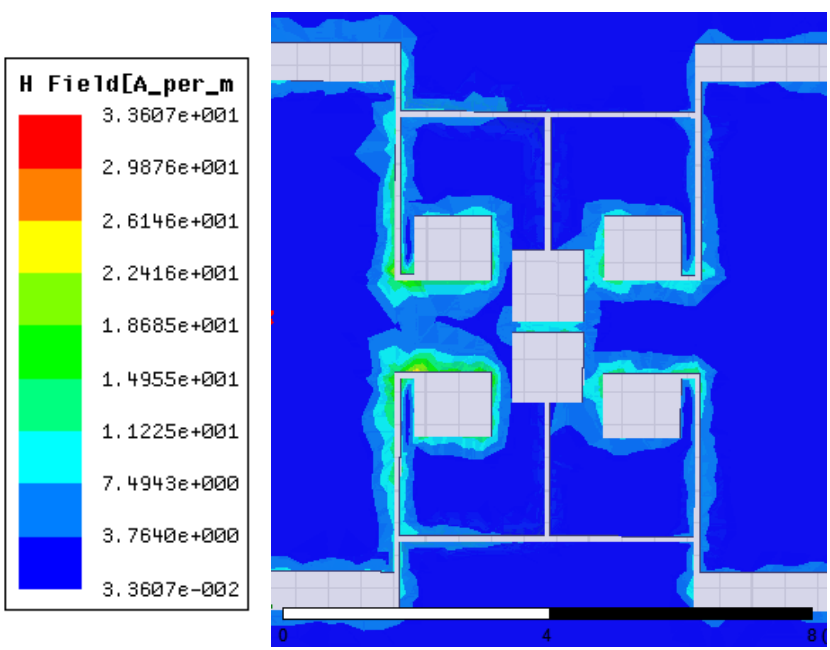

(a)
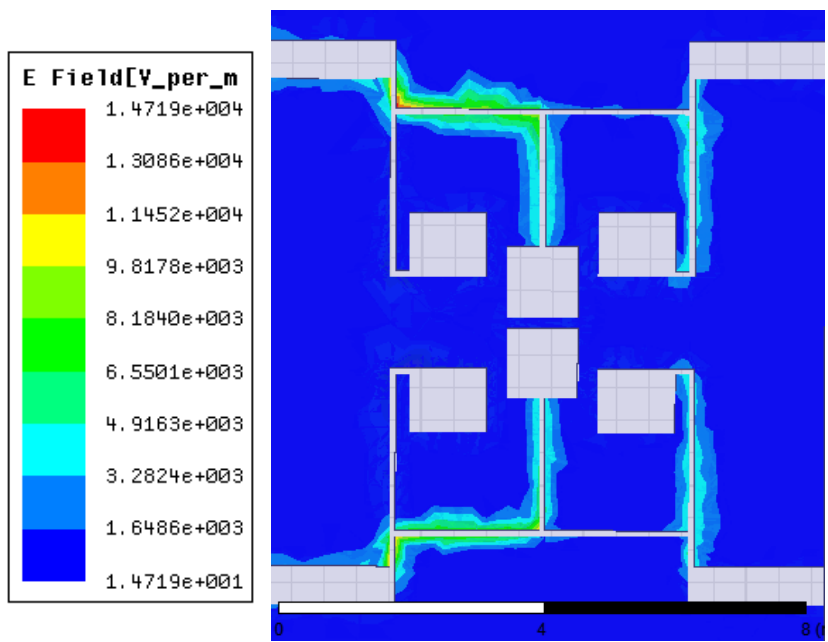

(b)

Figure 8: Field distributions of the proposed LUC (a) electric field (b) magnetic field.

\section{Experimental results}

The proposed LUC is fabricated on the low cost FR4 substrate with dielectric constant $\left(\varepsilon_{\mathrm{r}}\right)$ of 4.4 , the loss tangent factor $(\tan \delta) 0.023$, and the thickness $(h)$ of $1.57 \mathrm{~mm}$. The photograph of the fabricated LPF are depicted in Fig. 9.

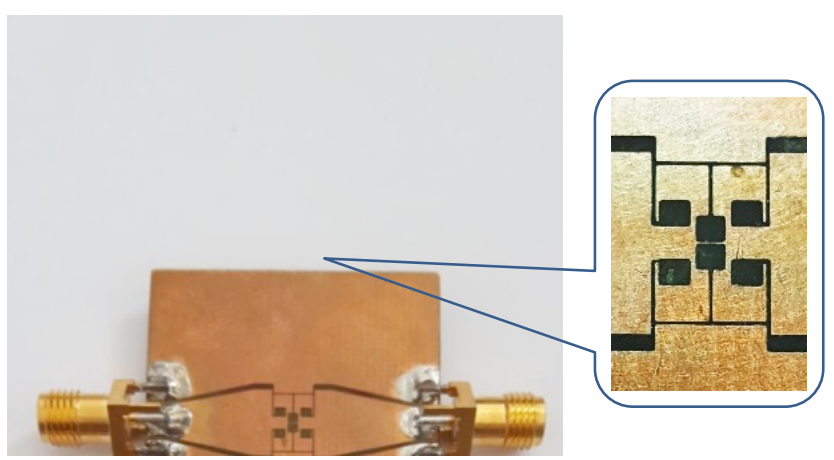

Figure 9: Photograph of the fabricated LUC.
The size of the fabricated LUC is $4.9 \times 8.7 \mathrm{~mm}^{2}$, approximately $0.16 \lambda_{\mathrm{g}} \times 0.29 \lambda_{\mathrm{g}}$, where $\lambda_{\mathrm{g}}$ is the free-space wavelength of the cut-off frequency. Measured results of the LUC are characterized in an HP8720C network analyzer. Fig. 10 shows the measured and EM simulation results of the fabricated LUC.

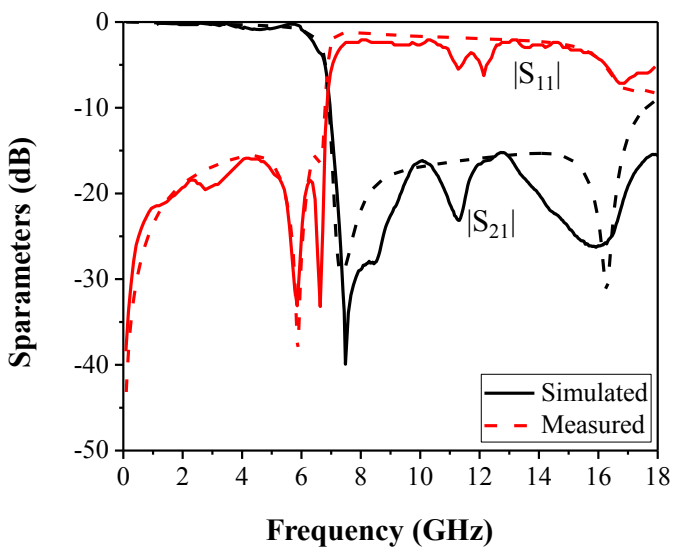

Figure 10: Measured (solid line) and simulated (dash line) frequency responses of the proposed LUC.

As shown in Fig. 10, the EM simulation shows good agreement with measured results. The fabricated LUC has a maximum insertion loss of $0.9 \mathrm{~dB}$ and a minimum return loss of $16 \mathrm{~dB}$ in the passband. Two transmission zeros are located at 7.5 and $15.9 \mathrm{GHz}$ with -39.9 and $-26.2 \mathrm{~dB}$, respectively. The stopband has an average rejection of $15 \mathrm{~dB}$ over a bandwidth of approximately $161.5 \%$. The roll-off rate is as high as $42.3 \mathrm{~dB} / \mathrm{GHz}$. A comparison of the proposed LUC with other reported compact CPW LUCs is provided in Table 1. Compared with the LUCs in the table, the proposed LUC exhibits high roll-off rate.

Table 1: Performance comparison of the LUC with other CPW LUCs already reported.

\begin{tabular}{ccccccc}
\hline & {$[16]$} & {$[1]$} & {$[11]$} & {$[3]$} & {$[5]$} & $\begin{array}{c}\text { This } \\
\text { work }\end{array}$ \\
\hline$f_{\mathrm{c}}(\mathrm{GHz})$ & 1.7 & 3 & 3.4 & 1.2 & 2 & 6.5 \\
$\Omega_{\mathrm{s}}=f_{\mathrm{s}} / f_{\mathrm{c}}$ & 1.47 & 2.33 & 1.47 & 2.4 & 1.45 & 1.15 \\
$L_{\mathrm{As}}(\mathrm{dB})$ & $>15$ & $>15$ & $>10$ & $>35$ & $>10$ & $>15$ \\
$\left(\begin{array}{l}\left.\text { up to } 3 f_{\mathrm{c}}\right) \\
\text { IL }(\mathrm{dB})\end{array}\right.$ & $<0.7$ & $<0.5$ & $<1$ & $<0.4$ & $<1.5$ & $<0.9$ \\
$\mathrm{RL}(\mathrm{dB})$ & $>15$ & $>15$ & $>20$ & $>24$ & $>8$ & $>16$ \\
$\left(\right.$ up to $\left.f_{\mathrm{c}}\right)$ & & & & & & \\
$\quad \mathrm{RR}$ & 24.3 & 8.5 & 20.6 & 33.5 & 35.5 & 42.3 \\
$(\mathrm{~dB} / \mathrm{GHz})$ & & & & & & \\
Size $\left(\lambda_{\mathrm{g}}{ }^{2}\right)$ & 0.066 & 0.012 & 0.007 & 0.002 & 0.011 & 0.046 \\
Substrate & FR4 & Teflon & FR4 & Rogers & FR4 & FR4 \\
\hline
\end{tabular}

Note: IL: Insertion Loss, $L_{\mathrm{AS}}$ : stopband attenuation, RL: Return Loss, RR: Roll-off Rate

\section{Conclusions}

A new lowpass filter unit cell (LUC) based on coupled parallel stepped impedance resonators (SIR) have been proposed in coplanar waveguide (CPW) technology. The transmission zeros and transmission poles have been investigated using the equivalent LC circuit model and the findings have been used to improve the stopband 
performance of the LUC. Coupled parallel SIRs with folded structures have been used as shunt resonators to increase the roll-off rate. The fifth-order LUC has been designed and fabricated. The stopband exhibits a sharp roll-off rate of 42.3 $\mathrm{dB} / \mathrm{GHz}$ and a rejection level better than $15 \mathrm{~dB}$ up to 2.5 times the cut-off frequency. Compact size, sharp roll-off and good stopband performance make the proposed LUC very promising for CPW filter applications in wireless communication systems.

\section{References}

[1] J.-W. No, and H. -Y. Hwang, "A design of cascaded CPW low-pass filter with broad stopband," IEEE Microw. Wirel. Compon. Lett. vol. 17, no. 6, pp. 427-429, 2007.

[2] F. Aznar, A. Velez, M. Duran-Sindreu, et al., "Ellipticfunction cpw low-pass filters implemented by means of open complementary split ring resonators (OCSRRs)," IEEE Microw. Wirel. Compon. Lett. vol,.19, no. 11, pp. 689-691, 2009.

[3] M. Duran-Sindreu, J. Bonache, and F. Martin, "Compact elliptic-function coplanar waveguide low-pass filters using backside metallic patterns," IEEE Microw. Wirel. Compon. Lett. vol.20, no. 11, pp. 601-603, 2010.

[4] R. Simons, Coplanar waveguide circuits, components, and systems, Hoboken: Wiley; 2004.

[5] T. Moyra, S. Kumar Parui, and S. Das, "Modeling and validation of coplanar waveguide elliptic filter using square open complementary split-ring resonator," Electromagn. vol. 32, no. 8, pp. 506-515, 2012.

[6] J.-S. Hong, and B. M. Karyamapudi, "A general circuit model for defected ground structures in planar transmission lines," IEEE Microw. Wirel. Componen. Lett. vol. 15, no. 10, pp. 706-708, 2005.

[7] J.-S. Lim, C.-S. Kim, Y.-T. Lee, and et al., "A spiralshaped defected ground structure for coplanar waveguide," IEEE Microw. Wirel. Componen. Lett. vol. 12, no. 9, pp. 330-332, 2002.

[8] A. A. Omar, N. I. Dib, K. Hettak, and et al., "Design of coplanar waveguide elliptic low pass filters," Int. J. RF Microw. Computer-Aided Eng. vol. 19, no. 5, pp. 540548, 2009.

[9] K. Hettak, N. I. Dib, A. A. Omar, and et al., "A useful new class of miniature CPW shunt stubs and its impact on millimeter-wave integrated circuits," IEEE Trans. Microw. Theory Tech. vol. 47, no. 12, pp. 2340-2349, 1999.

[10]H.-K. Chiou, and I.-S. Chen. "A compact and low loss V-band lowpass filter using coplanar waveguide structure," Progress In Electromagnetics Research Symposium, Mar 23-27; Beijing, China. pp. 1743-1745, 2009.

[11] Y. Zou, X. Hu, S. He, et al, "Compact coplanar waveguide low-pass filter using a novel electromagnetic bandgap structure," $7^{\text {th }}$ International Symposium on Antennas, Propagation and EM Theory, Oct 26-29; Guilin, China, 2006.

[12]F. Martin, F. Falcone, J. Bonache, et al, "Dual electromagnetic bandgap CPW structures for filter applications," IEEE Microw. Wirel. Compon. Lett. vol. 13, no. 9, pp. 393-395, 2003.

[13] J. Sor, Y. Qian, T. Itoh, "Miniature low-loss CPW periodic structures for filter applications," IEEE Trans. Microw. Theory Tech. vol. 49, no. 12, pp. 2336-2341, 2001.

[14]J.-S. Hong, Microstrip filters for RF/microwave applications, $2^{\text {nd }}$ Ed. Hoboken, N.J: Wiley; 2011.

[15] G. I. Zysman, A. K. Johnson, "Coupled transmission line networks in an inhomogeneous dielectric medium," IEEE Trans. Microw. Theory Tech. vol. 17, no. 10, pp.753-759, 1969.

[16] C. -C. Huang, N. -W. Chen, H. -J. Tsai, et al., "A coplanar waveguide bandwidth-tunable lowpass filter with broadband rejection," IEEE Microw. Wirel. Compon. Lett. vol. 23, no. 3, pp. 134-136, 2013. 